\title{
Aquaplanet Simulations of Tropical Cyclones
}

\author{
Timothy M. Merlis ${ }^{1}$ (D) $\cdot$ Isaac M. Held ${ }^{2}$
}

Published online: 8 June 2019

(C) The Author(s) 2019

\begin{abstract}
Purpose of Review Tropical cyclones (TCs) are strongly influenced by the large-scale environment of the tropics and will, therefore, be modified by climate changes. Numerical simulations designed to understand the sensitivities of TCs to environmental changes have typically followed one of two approaches: single-storm domain sizes with convection-permitting resolution and uniform thermal boundary conditions or comprehensive global high-resolution (about $50 \mathrm{~km}$ in the horizontal) atmospheric general circulation model (GCM) simulations. The approaches reviewed here rest between these two and are an important component of hierarchical modelling of the atmosphere: aquaplanet TC simulations.

Recent Findings Idealized model configurations have revealed controls on equilibrium TC size in large-domain simulations of rotating radiative-convective equilibrium. Simulations that include differential rotation (spherical geometry) but retain uniform thermal forcing have revealed a new mechanism of TC propagation change via storm-scale dynamics and show a poleward shift in genesis in response to warming. Simulations with Earth-like meridional thermal forcing gradients have isolated competing influences on TC genesis via shifts in the atmospheric general circulation and the temperature dependence of TC genesis in the absence of mean circulation changes.

Summary Aquaplanet simulations of TCs with variants that include or inhibit certain processes have recently emerged as a research methodology that has advanced the understanding of the climatic controls on TC activity. Looking forward, idealized boundary condition model configurations can be used as a bridge between GCM resolution and convection-permitting resolution models and as a tool for identifying additional mechanisms through which climate changes influence TC activity.
\end{abstract}

Keywords Tropical cyclone $\cdot$ Aquaplanet $\cdot$ Climate model $\cdot$ Climate change

\section{Introduction}

Tropical cyclones (TCs, also known as hurricanes and typhoons) are a destructive component of the climate system. Given their importance, both observational analyses and numerical simulations of TCs are valuable research approaches $[1 \bullet]$. There is a longstanding desire to perform initialized, realtime forecasts to enable accurate prediction of TC track and intensity to minimize the loss of human life and property dam-

This article is part of the Topical Collection on Convection and Climate

Timothy M. Merlis

timothy.merlis@mcgill.ca

1 Atmospheric and Oceanic Sciences, McGill University, 805 Sherbrooke Street West, Montreal, QC H3A 0B9, Canada

2 National Oceanic and Atmospheric Administration, Geophysical Fluid Dynamics Laboratory, Princeton, NJ, USA age from these powerful storms. Numerical simulation has also been used for many decades to do process studies, designed to elucidate the fundamental controls on TCs (e.g., [2]).

Anthropogenic climate change provides an important motivation to identify how a warming tropical environment affects TCs. Given the well-documented environmental controls on TCs' intensity, genesis, and tracks, climate model projections of future climates inform expectations for future TC activity. There is a consensus expectation about the projection for the maximum intensity, based on a combination of physical modelling and theory. Other measures of TC activity, however, have larger uncertainty. An illustrative example arises when trying to solely use observational estimates from today's climate together with information about climate change obtained from coupled model simulations for TC genesis: different environmental genesis indices may be equally consistent with today's climate yet project different changes in future TC genesis. For example, Vecchi et al. (2008) [3] show that different indices based on sea surface temperature (SST) 
provide plausible reconstructions of historical TC activity, yet divergent future projections. Likewise, multivariate genesis indices can have different weights of positive (humidity) and negative (vertical wind shear) variables or somewhat different variables (such as measures of tropospheric humidity) that lead to different projections for the future (e.g., [4-6]). This suggests a need to go beyond empirical approaches and highlights the importance of physical models of the tropical atmosphere.

General circulation model (GCM) simulations of TC activity have improved since the mid-2000s (e.g., [7-11, 12•]). These simulations typically have reasonable geographic and seasonal distributions of TC genesis and therefore global TC number. They also simulate outer TC size that compares well with observations [13]. However, their intensity distributions are sensitive to convective and other sub-grid scale parameterization $[14,15]$ and are biased low at readily achievable resolutions $(\sim 50 \mathrm{~km})$, with improve distributions as horizontal resolution increases [e.g., 16]. This suggests that the processes controlling TC genesis and TC intensity are not intimately linked, and the genesis investigations in TC-permitting GCMs have led to the expectation of fewer TCs in a warmed future climate $[10,17]$, though the mechanism for this reduction is not fully understood.

Contemporaneously, climate change-motivated single-TC simulations furthered the understanding of environmental controls on intensification (e.g., 18-20]). These simulations often use idealized boundary conditions (BCs) of doubly periodic $f$-plane geometry with a homogeneous thermal forcing (prescribed uniform SST, in particular), run at sufficiently high, "cloud-resolving model" (CRM) resolution $(\sim 1 \mathrm{~km})$ to capture storm intensity (Fig. 1a). These studies illustrate the value of idealized BCs in understanding how TC intensification changes with the mean thermodynamic environment of the tropics. It is then natural to adopt a similar, idealized BC approach in GCMs.

The canonical simplification to atmospheric GCMs, which has been used extensively to examine large-scale climate changes, is to simplify the lower BC to that of a watercovered surface or "aquaplanet." This is typically done in a manner that eliminates zonal asymmetries (Fig. 1d). Given the climate's dominant variations are in latitude, this is a useful framework to understand the response of the Hadley circulation, extratropical storm tracks, the meridional structure of temperature, and the zonal-mean precipitation to climate changes (e.g., [21-24]). The extent to which this is a useful simulation framework to understand climate influences on TCs is, perhaps, less obvious. Regionally specific aspects of the controls on TCs (e.g., the relationship to African easterly waves) will be altered or eliminated by the use of aquaplanet BCs. However, there are successful applications of aquaplanet simulations of TCs - similar to CRM simulations of a single $\mathrm{TC}$ - that are valuable for a range of specific TC-climate research questions. The aim of this review is to highlight successful uses of aquaplanet simulations for TC research and outline future promising directions using this approach. In particular, comparisons of idealized BCs between CRM simulations and GCM simulations is a promising avenue of evaluating GCM parameterizations.

In what follows, we review the choices of simulation domain and BCs that have been used for TC aquaplanet simulations ("Simulation Domain and Boundary Conditions"). Then, we review the recent scientific results that have been obtained using this approach ("Recent Scientific Results"). Last, we discuss the outlook for this research approach and suggest promising future directions (“Outlook").

\section{Simulation Domain and Boundary Conditions}

\section{Simulation Domain and Thermal Forcing}

Earth's rotation is critical to TCs, as is clear from the absence of near-equator TCs (e.g., [25]). Therefore, the minimal simulation domain is to have a non-zero, but constant Coriolis parameter: $f$-plane geometry (Fig. 1a and b). For small domains, a single TC is simulated and many studies consider the intensification in initial value problem simulations (e.g., 18-20, 26-28]), and these simulations are critical in developing and evaluating theories for the dynamics of individual TCs [reviewed by 29]. There are also single-TC simulations of longer time integrations [e.g., 30-32], which connects the single-TC research to the boundary value problem calculations performed with large-domain rotating radiativeconvective equilibrium (RCE). As the domain size is increased to those comparable to Earth's surface area, multiple TCs are simultaneously simulated (Fig. 1b), and when run to a statistical steady state with uniform thermal forcing, this is a rotating RCE. The "Large-Domain, Rotating Radiative Convective Equilibrium" section reviews large-domain rotating RCE simulation results.

Earth's spherical geometry leads to two fundamental inhomogeneities for climate. First, the projection of Earth's spin axis into the component normal to the surface - determining the Coriolis force acting on the horizontal wind - varies with latitude (Fig. 2a). This gives rise to the $\beta$ effect, i.e., the northsouth variation of the Coriolis parameter $f$, which has fundamental dynamical consequences for TC storm motion and tracks (Fig. 2b and c). A configuration that is a step toward comprehensive simulations of Earth's atmosphere from largedomain rotating RCE is then spherical geometry with uniform thermal forcing (Fig. 1c). The "Spherical Geometry With Uniform Thermal Forcing" section reviews the results of simulations in this configuration.

Earth's spherical geometry also leads to the dependence of the solar zenith angle on latitude (Fig. 3a), giving rise to 
Fig. 1 Domains and thermal forcing for idealized tropical cyclone model configurations. Uniform thermal forcing, doubly periodic, constant Coriolis parameter $(f$-plane) rotating configurations for a small and $\mathbf{b}$ large domains, which form rotating radiative-convective equilibria for long time integrations. Spherical geometry domains, where $\beta=\partial_{y} f \neq 0$ with c uniform and $\mathbf{d}$ Earth-like thermal forcing (meridional insolation gradient $\Delta_{s} \neq 0$ ) with shading indicating surface temperature (yellow indicating warmer temperature than blue). Note the TC size is exaggerated compared to the domain size in these schematics

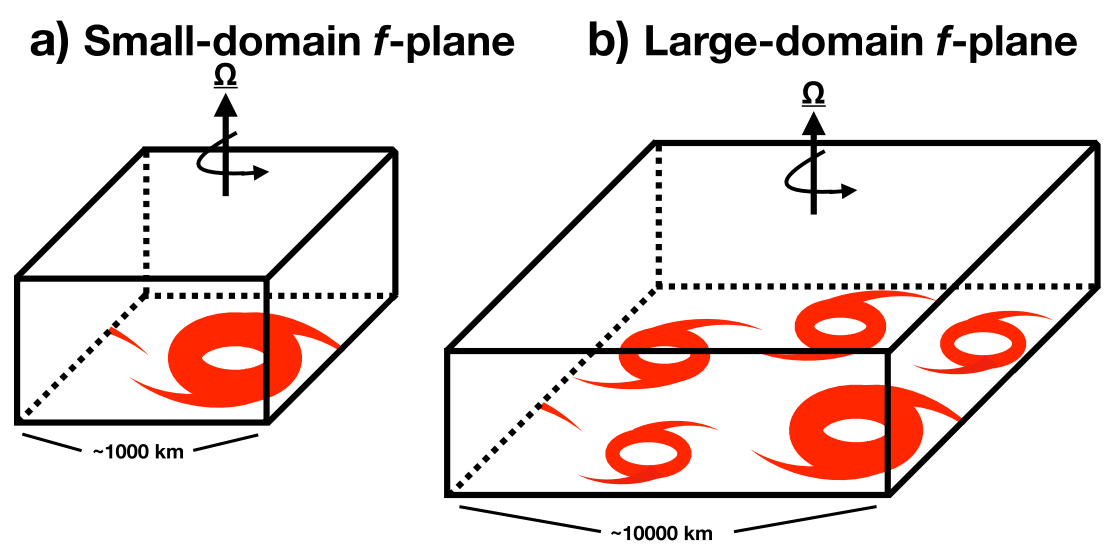

C) Spherical geometry, uniform thermal forcing
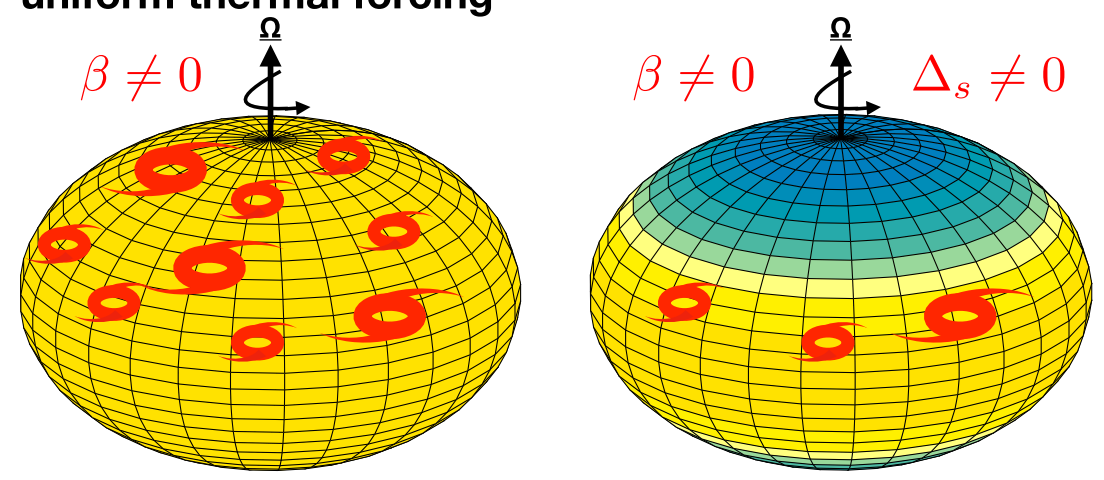

equator-to-pole insolation $\left(\Delta_{S}\right)$ and temperature contrasts. Insolation gradients may take the form of perpetual equinox conditions and include the diurnal cycle (e.g., [33]) or idealized meridional distributions that approximate the annual mean insolation and are time-independent (e.g., [34]). Enabling these thermodynamic and concomitant dynamic inhomogeneities (e.g., vertical wind shear in thermal wind balance with meridional temperature gradients) that suppress extratropical TC activity $[4,35]$ leads to "Earth-like" aquaplanets (Fig. 1d). The "Earth-Like Aquaplanets" section reviews TC-permitting simulation results in this configuration.

This series of model configurations was outlined in the review of Jeevanjee et al. [36•] as a possible "elegant tropical model hierarchy." Hierarchical modelling of the atmosphere, with an emphasis on larger scales, has also been recently reviewed by [37]. Model hierarchies often prove to be useful when they are used across a range of scientific questions [38], so while we review TC research here, there are a broader range of fundamental questions of tropical climate that the same configurations can be used to address ("Outlook").

We focus on results performed across this hierarchy of simulation configurations performed with the Geophysical Fluid Dynamics Laboratory's High-Resolution Atmospheric Model (HiRAM) GCM, which has a high-quality simulation of climatological, interannual, and interdecadal TC activity in comprehensive $\mathrm{BC}$ simulations with prescribed, interannually varying, observed SST [9, public release available at https:// www.gfdl.noaa.gov/hiram-quickstart/]. The observational evaluation of comprehensive $\mathrm{BC}$ simulations is a critical step in working with a model hierarchy and is one that should be undertaken with global CRMs as they emerge. HiRAM is a GCM with which simulations in all configurations described have been performed. Where possible, we compare with CRM or other high-resolution GCM results in these configurations.

\section{Lower Boundary Condition}

An aquaplanet $\mathrm{BC}$ is a water-covered, saturated surface. The lower surface BC can either have a prescribed SST [33] or a slab ocean BC (e.g., [43, 44]). Prescribed SST BCs have the virtue that they can be used to isolate differences in the atmospheric simulations and are therefore routinely used in model intercomparisons, including aquaplanet fifth phase of the coupled model intercomparison project CMIP5 simulation design $[45,46]$ and the high-resolution GCM intercomparison described in Walsh et al. [47]. This has been used as a lower $\mathrm{BC}$ in Earth-like aquaplanet TC-permitting GCM simulations by Li et al. [48] and Ballinger et al. [34].

Slab ocean BCs allow the SST to respond to turbulent surface fluxes and radiative fluxes, thereby closing the surface energy budget without unphysical implied fluxes. This has 
Fig. 2 Spherical geometry with uniform thermal forcing simulates the effects on tropical cyclones of the inhomogeneous Coriolis parameter. a Coriolis parameter's latitudinal variation, the $\beta$-effect. b The $\beta$-drift mechanism for westward and poleward TC propagation, where $\mathrm{H}$ and $\mathrm{L}$ are regions of high and low relative vorticity induced by the conservation of absolute vorticity. c The average track of a spherical geometry GCM simulation with uniform thermal forcing follows $\beta$-drift's poleward and westward trajectory (reprinted from [39]). d, e Polar projection of instantaneous surface windspeed for two SSTs (reprinted from [40.]) with $30^{\circ}$ latitude circles indicated with dotted lines

\section{Spherical geometry, uniform thermal forcing}

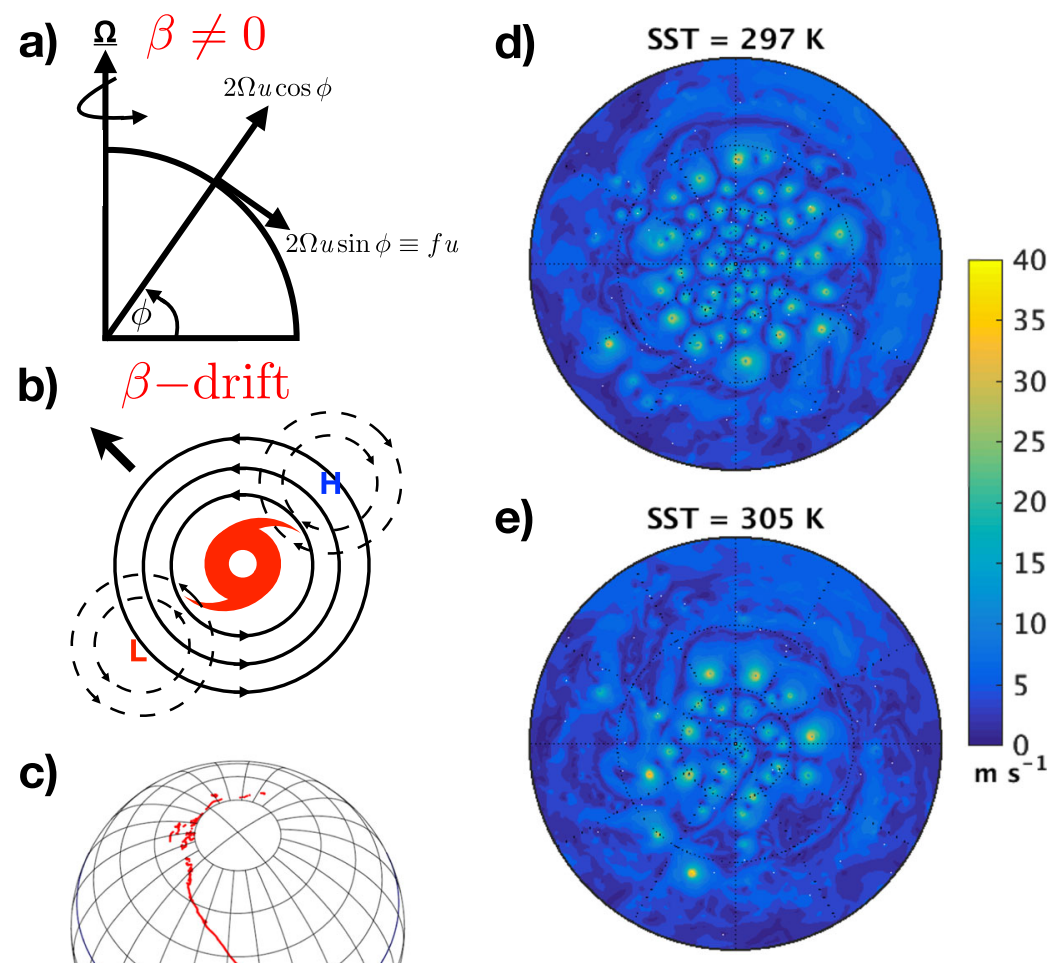

been used in aquaplanet GCM simulations of TCs by Merlis et al. [40], Viale and Merlis [41], and Zhou et al. [49]. The turbulent latent heat fluxes are critical to TC intensification and can reach large values (order $1000 \mathrm{Wm}^{-2}$ ) near the TC center [50]. This is a cooling tendency on the surface that prescribed SST simulations neglect [a sensitivity systematically examined in slab ocean simulations of large-domain rotating RCE in 49]. However, the slab ocean BC is assumed to have an infinite diffusivity and therefore vertically uniform temperature, which precludes the mixing effects of TC stirring cold water up from the subsurface ocean [e.g., 51, 52].

\section{Recent Scientific Results}

\section{Large-Domain, Rotating Radiative Convective Equilibrium}

There have been many initial value problem calculations with small domains $(\approx 1000 \mathrm{~km}$; Fig. 1a) with convection-permitting resolution (CRMs). These typically have prescribed SST and are integrated for $\approx 10$ days, as is relevant for TC intensification from an initial vortex (e.g., [19]). The climate complement of this calculation is a boundary value problem, integrated to a statistically steady state $(\approx 100$ days $)$ with a domain that is sufficiently large $(\approx 10,000 \mathrm{~km}$; Fig. $1 \mathrm{~b})$ to enable the simulation of multiple TCs [pioneered by 53]. Large-domain rotating RCE simulations have been performed with both GCM (e.g., $[53,54])$ and CRM [55] resolution, though Khairoutdinov and Emanuel [55] increased the Coriolis parameter by about an order of magnitude to allow multiple TCs in a smaller domain. A variant of large-domain rotating RCE has been performed with spherical-domain GCMs with the Coriolis parameter is set to a uniform value at all latitudes [56, a configuration with an inconsistency in angular momentum conservation, Fig. 2a]. This may be an easier configuration to set up in spherical geometry GCM dynamical cores than rotating RCE with Cartesian $f$-plane geometry and plausibly does not distort TC dynamics. Note, however, that this is a distinct configuration from the spherical geometry with uniform thermal forcing configuration described in "Spherical Geometry With Uniform Thermal Forcing."

In large-domain, rotating RCE simulations, TCs develop and fill the domain. The statistical equilibrium is one of infrequent genesis and lysis. The dry, subsiding region away from the TCs is a thermodynamic barrier that may inhibit TC-TC interactions like mergers. The scientific questions that have been addressed include the equilibrium TC size and intensity, 


\section{Earth-like Aquaplanets}

a)

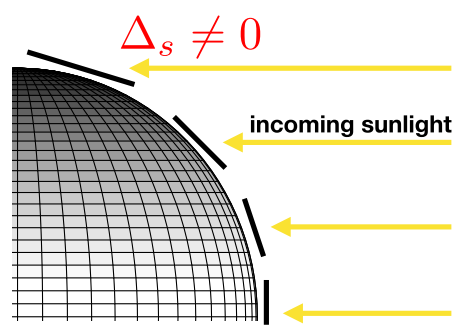

c)

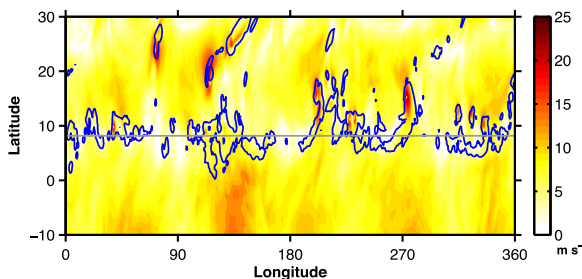

e)

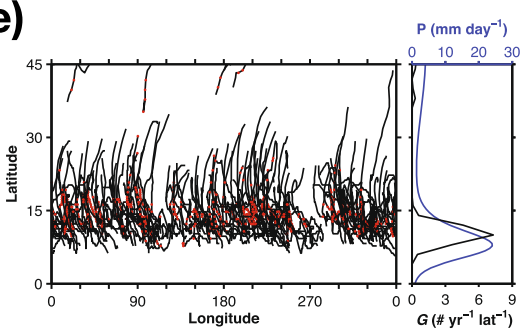

b)
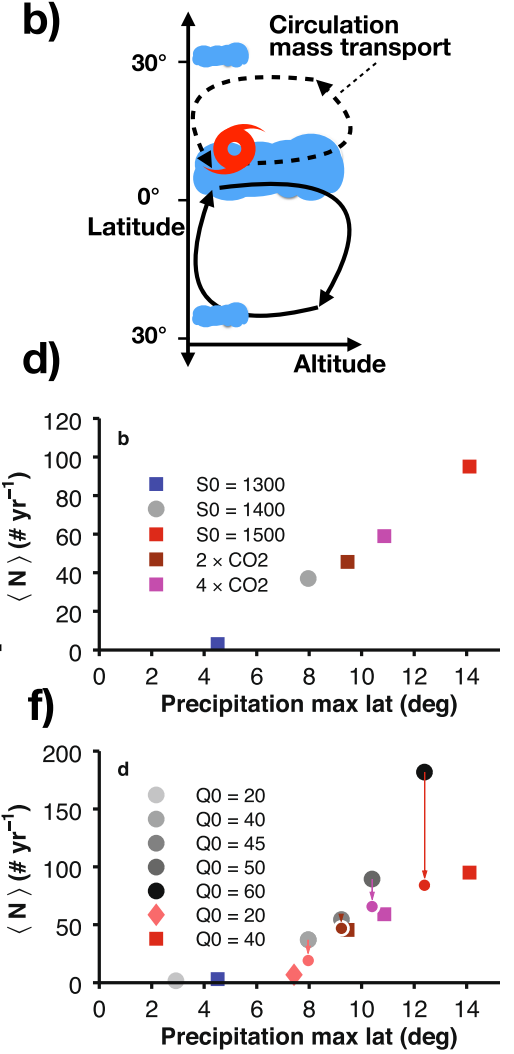

$\mathrm{Wm}^{-2}$ (reprinted from [42]). e Aquaplanet GCM simulation TC tracks and zonal-mean precipitation and genesis frequency (reprinted from [42]). $\mathbf{f}$ Global number of TCs in slab ocean simulations with radiatively forced climate changes and perturbed ocean heat transport vs. ITCZ latitude, with $Q 0$ value indicated the magnitude of prescribed ocean heat transport convergence with downward arrows indicating the estimate that warmed climates have $10 \% \mathrm{~K}^{-1}$ fewer TCs than corresponding control climates with similar ITCZ position (reprinted from [42])

the TCs themselves (e.g., the tropospheric humidity distribution differs from small-domain RCE or comprehensive GCM simulations of Earth). These differences motivate a careful analysis of spherical domain simulations, where TCs can propagate, leaving the genesis environment to be restored by non-TC convective, radiative, and dynamical tendencies (Fig. 1c).

\section{Spherical Geometry With Uniform Thermal Forcing}

Spherical (or $\beta$-plane) geometry introduces dynamical effects arising from the non-uniform Coriolis parameter. The nonlinear self-advection of tropical cyclones or " $\beta$ drift" accounts for the poleward and westward TC propagation that is a ubiquitous feature of TC tracks [57]. The relative vorticity perturbations induced by absolute vorticity conservation (equivalently, barotropic potential vorticity conservation) of the poleward vs. equatorward flowing air gives rise to secondary circulation tendencies that induce a poleward and westward TC time to establish and the environment is strongly modified by 
motion (Fig. 2b). Therefore, spherical or $\beta$-plane geometry with uniform thermal forcing is the minimal simulation configuration that allows for TC propagation away from the genesis region, while retaining the homogeneous BCs for thermodynamic variables. The first published study that analyzed TCs in this configuration was Shi and Bretherton [39], who showed the typical TC track underwent $\beta$ drift all the way to the pole (Fig. 2c)! The resulting turbulent equilibrium is one where TCs densely populate a polar cap (Fig. 2d, e), and there are frequent TC-TC interactions (including the "Fujiwhara effect" of co-rotation, animation available here https:// vimeo.com/159153890) with merger events that are more common than in large-domain rotating RCE.

This simulation configuration had previously been used to examine Hadley circulations in the regime where the axisymmetric theories [58] do not support overturning circulations because of the absence of meridional thermal gradients [59-61]. Note that we avoid using the term "global RCE" for this configuration, as the simulated time-mean divergent circulations (e.g., Fig. 2 of [62]) affect the troposphere's energy balance, though other authors have used this term to describe this model configuration. Subsequent to Shi and Bretherton [39], Merlis et al. [40•] showed the temperature sensitivity of the number, intensity, and genesis rate in this configuration. These were compared to the large-domain rotating RCE $f$-plane simulations of Zhou et al. [54], and many of the sensitivities qualitatively carry over. For example, Merlis et al. [40•] found that there were fewer TCs with warming, a sensitivity also found in another GCM [63], and that the genesis rate decreased with warming. Chavas and Reed [64•] systematically varied rotation rate and planet radius to more thoroughly assess the extent to which $f$-plane sensitivities carry over to spherical geometry. The TC pressure-wind relationship in this configuration has also been compared with a comprehensively configured GCM and observations, and there is consistency with a theoretical relationship based on gradient wind balance that holds across the model hierarchy and in observations [65॰]. A new scientific result was that the TC propagation speed, via $\beta$ drift, increased with warming [40॰]. The increased $\beta$ drift with warming arises from both larger storm radius and intensity (Fig. $2 \mathrm{~d}$ and e). This increased $\beta$ drift with warming has also been found in single-TC, convection-permitting simulations [Chapter 3 of 66]. The observed slowdown in TC propagation [67] is affected by steering wind changes of the larger-scale atmospheric circulation, and this discrepancy is suggestive that $\beta$ drift changes revealed by this model configuration are subdominant to other mechanisms.

These simulations have a well-defined, low-latitude (near $15^{\circ}$ ) TC genesis region that moves poleward with warming, leaving an enlarged TC-free equatorial zone (Fig. 2d,e). Interestingly, this is consistent with downscaled TC simulations of substantially warmed, comprehensive BC GCM simulations (Fig. 3 of [68]). It is also potentially relevant to observed poleward shifts in TC statistics (e.g., [69]), though the simulated poleward shift per unit of tropical warming is about an order of magnitude smaller than observed. This type of discrepancy implies either changes beyond those captured by this model configuration are important or internal variability is a substantial component of observed changes. One interpretation of the poleward shift in genesis in simulations with uniform thermal forcing is to consider it an expansion of the "forbidden" near-equatorial zone where the requirement that the TC size is small enough to fit within a single hemisphere is not met [64•]. As equilibrium TC size depends on thermodynamic quantities, like potential intensity $V_{P I}$ or the dry static stability $(\propto N)$ that increase with warming, the minimum required distance from the equator increases as this storm size increases. However, the controls on TC size at genesis likely differ from the better-understood equilibrium size and spherical geometry has other factors that influence genesis (weak time-mean divergent circulations and convectively coupled waves).

\section{Earth-Like Aquaplanets}

Moving from uniform thermal forcing to Earth-like aquaplanets, an extratropical baroclinic region with vertical wind shear emerges (Fig. 1c-d) and strong time-mean divergent circulations shape the tropical regions favorable for TC genesis (Fig. 3b, c, e). One could systematically vary the meridional SST gradient to connect these regimes, a parameter variation that Fedorov et al. [70•] examined. They found that extratropical regions of warm-core cyclone (TC) activity (near $\approx 40^{\circ}$ ) was eliminated when the equator-to-pole SST contrast was increased from a small value of $14 \mathrm{~K}$ to a value more characteristic of Earth's late summer of 23K.

For interactive SST BCs, aquaplanets with Earth-like thermal forcing have been performed with perpetual equinox, perpetual annual mean, or seasonally varying insolation. As is well known observationally, the seasonal cycle is important for TCs. The seasonal cycles of the general circulation and surface climate in aquaplanets with slab ocean BCs depend on the surface heat capacity, and these sensitivities are the subject of investigation in and of themselves (e.g., [71-73]). Therefore, time-independent, hemispherically asymmetric forcing (akin to perpetual late-summer conditions) has been used for Earth-like aquaplanets in TC research. This is also computationally advantageous, as a shorter spin-up time is required to reach an equilibrated climate state $(\approx 5$ years rather than $\approx 10$ years).

As the degree of hemispheric asymmetry is varied in Earthlike aquaplanets, there are large sensitivities in TC activity. In the hemispherically symmetric case, there may be little TC activity because the intertropical convergence zone (ITCZ) and concomitant high free-tropospheric humidity are on the 
equator, where the Coriolis parameter is zero. Figure 3 (bottom) shows the increase in TC genesis as the ITCZ is displaced from the equator [42]. These simulations have time-independent hemispherically symmetric insolation and a hemispherically asymmetric prescribed cross-equatorial ocean heat transport convergence, following Kang et al. [44]. As the cross-equatorial ocean heat transport is increased (shown in gray symbols), the ITCZ shifts further off equator and the number of TCs increases strongly: In this GCM, it is a $\approx 40 \%$ increase per degree latitude ITCZ shift (measured by the latitude of maximum precipitation [42]). We note that the simulations with more poleward ITCZ latitudes also have wider convergence zones (see review by [74]), a factor that may also be conducive to TC genesis as the meridional scale of the high humidity region is larger.

The Earth-like aquaplanet simulations shown in Fig. 3d have a distinctive response to radiatively forced warming. For an unchanged value of cross-equatorial ocean heat transport, there is an increase in TC genesis. This stands in contrast to comprehensively configured version of this GCM. The increase in aquaplanet TCs arises as a result of the competing effects of warming, which tends to reduce genesis with unchanged ITCZ location, and a poleward ITCZ shift, which can occur with constant cross-equatorial ocean heat transport because of atmospheric radiative feedbacks and stratification changes [75•], that tends to increase genesis. This is captured by the following partial sensitivities for the global TC number $N$ :

$$
\begin{aligned}
& N^{-1} \partial N / \partial \phi_{I} \approx 40 \%\left({ }^{\circ} \text { lat }\right)^{-1} \\
& N^{-1} \partial N / \partial T \approx-10 \% \mathrm{~K}^{-1},
\end{aligned}
$$

with ITCZ latitude $\phi_{I}$ and tropical-mean surface temperature $T$. For this GCM, the ITCZ shifts in response to warming by about $+0.6^{\circ}$ lat $K^{-1}$, implying the ITCZ-related increase is larger than the decrease in TCs from warming with unchanged ITCZ position. Figure $3 \mathrm{f}$ shows this simple estimate of how the number of TCs in the simulations with Earth-like $\mathrm{CO}_{2}$ and solar constant would be expected to change if the warming sensitivity was taken into account (downward pointing arrows in Fig. 3f). For example, the $4 \times \mathrm{CO}_{2}$ simulation has an ITCZ near $11^{\circ}$ (purple square in Fig. $3 \mathrm{f}$ ) and is $\approx 3 \mathrm{~K}$ warmer in the tropics than the $1 \times \mathrm{CO}_{2}$ with similar ITCZ latitude (second darkest gray circle in Fig. 3f), implying $\mathrm{a} \approx 30 \%$ reduction of TCs would be expected from warming (2). The reduction in explicitly simulated TCs in the $4 \times \mathrm{CO}_{2}$ simulation (purple square in Fig. 3f) is indeed approximately consistent with the estimated reduction (purple circle in Fig. 3f). It is an intriguing possibility that the mechanism underlying the reduction in genesis with unchanged ITCZ position in the Earth-like aquaplanets is the same as that of the aquaplanet with uniform thermal forcing; this has not been investigated and is a promising direction toward building confidence in the robustness of comprehensive GCM results, which typically have genesis reductions in warming scenarios.

The poleward ITCZ shift in response to $\mathrm{CO}_{2}$ is a robust response in Earth-like aquaplanet simulations, according to a GCM intercomparison [75•]. We note that the seasonal sensitivity of the ITCZ may respond differently than these Earthlike aquaplanets with time-independent BCs. Systematic investigation of the TC genesis response to ITCZ latitude have not been examined in other TC-permitting GCMs, an important sensitivity to assess in other models.

The sensitivities appear broadly similar between $\mathrm{CO}_{2}$ and solar radiative forcing in Fig. 3b. A closer examination reveals that there is a larger increase in response to $\mathrm{CO}_{2}$-forced warming than that of solar forcing [41]. This is related to a radiative forcing agent dependence of the ITCZ shift: there is a larger shift provoked by $\mathrm{CO}_{2}$, per unit warming or unit radiative forcing, that arises from differences in the spatial structure of the radiative forcing [41]. Solar forcing is larger magnitude in low latitudes than $\mathrm{CO}_{2}$ forcing, which implies a more modest ITCZ shift, according to energetic theories for ITCZ shifts [76]. This is dynamical mechanism for radiative forcing agent dependence of TC responses is distinct from proposed thermodynamic mechanisms associated with changes in potential intensity changes $[77,78]$. That thermodynamic mechanism of radiative forcing agent dependence is related to variations between solar and greenhouse forcing in altering tropicalmean energy budgets $[79,80]$.

Here we have reviewed the genesis results in Earth-like aquaplanets, but other aspects such as TC track, lifetime, average intensity (see [34]), influences of changes in the midlatitude atmospheric circulation, and extratropical transition are fruitful avenues of future inquiry.

\section{Outlook}

The last decade of research has seen significant progress in using idealized boundary condition (BC) configurations of atmospheric models to simulate and understand tropical cyclones (TCs). A hierarchy of domains and thermal forcing have filled a gap between the small-domain $f$-plane simulations with uniform thermal forcing of a single-TC and the global TC-permitting resolution GCM simulations with comprehensive Earth BCs (Fig. 1). This hierarchy includes largedomain rotating radiative-convective equilibria, where a turbulent equilibrium emerges with multiple TCs (Fig. 1b). Dynamical effects of spherical geometry can then be introduced in spherical (or $\beta$-plane) geometry simulations with uniform thermal forcing, where a well-defined subtropical TC genesis rate can be quantified because the $\beta$-drift propagation mechanism is a TC removal mechanism from these latitudes (Figs. 1c and 2b). Then, inhomogeneous thermal forcing can be introduced in spherical domain simulations 
with zonally symmetric, but Earth-like thermal forcing and BCs ("Earth-like" aquaplanets). This creates extratropical regions with meridional temperature gradients and the concomitant vertical wind shear, which are unfavorable for TCs, and divergent circulations that shape favorable low-latitude regions for TC genesis (Figs. 1d and $3 b$ ).

The results to date have shown environmental temperature and rotation rate sensitivities, and large-scale circulation effects that are valuable for understanding TC sensitivities and may help decompose the results of global GCM simulations with comprehensive Earth BCs. Proceeding through the hierarchy is also illustrative in highlighting sensitivities when there are differences between configurations. For example, large-domain rotating RCE, spherical geometry with uniform thermal forcing, and comprehensive Earth BC simulations in HiRAM have reduced numbers of TCs with warming when perturbed by uniform SST increases, yet the Earth-like aquaplanet has an increase in the number of TCs when a slab ocean $\mathrm{BC}$ with an energetically consistent pattern of warming emerges in response to increased $\mathrm{CO}_{2}$.

In the analysis of the HiRAM GCM, the sensitivity of genesis frequency changes in the uniform thermal forcing is broadly [40॰] similar to the Earth-like aquaplanet response to warming [42], which in turn, is broadly similar to comprehensive $\mathrm{BC}$ perturbation simulations $[9,11]$. This is suggestive of the same underlying mechanism for the genesis changes, but quantitative assessments of them (following, e.g., [81]) have not been made across the hierarchy.

The Earth-like aquaplanet configuration naturally emphasizes the role of north-south (Hadley) circulation changes on TCs. However, zonal asymmetries are important in determining the climatological TC activity [including low-frequency variations 82,83 ] and the zonal asymmetric component of changes are important in comprehensive GCM simulations of TC changes (e.g., Fig. 16 of [9]). An appealing direction for further research is to introduce zonal asymmetries, either with land surfaces [84•] or with oceanic lower BCs (see preliminary explorations in $[85,86])$.

Simulations across this range of model configurations have been performed with GCMs that parameterize convection and, in certain configurations, with large-domain convection-permitting resolution. These comparisons across model type are suggestive of the utility of using idealized TC-permitting configurations for model development. Concrete examples of this include variable-resolution or stretched-grid dynamical cores $[87,88]$ and approaches to make CRMs more computational affordable [89]. The intercomparison of non-rotating RCE [90•] may be extended to some of the idealized configurations described here, such as uniform thermal forcing in spherical or $\beta$-plane geometry. Last, it is worth noting that Earth-like aquaplanet intercomparisons, such as that of CMIP5, typically use hemispherically symmetric SST distributions that are unfavorable for TC genesis. It is, therefore, advisable to systematically include hemispherically asymmetric SST distributions in future aquaplanet intercomparisons.

Looking forward, there are a number of scientific questions that are ripe for assessment in the idealized model configurations described here. A central question of the tropical climate involves the mechanisms and extent to which convection and clouds aggregate [91, 92]. Temperature sensitivity of nonrotating convective aggregation has been found in CRM and GCM simulations [93, 94], which may have implications for climate feedback processes. The introduction of rotation gives rise to TCs and the intraseasonal Madden-Julian Oscillation (MJO), and these may have distinct temperature sensitivity that modify the extent to which the non-rotating aggregation results carry over to the rotating sphere. Within the context of differentially rotating geometry with uniform thermal forcing, a basic question concerns the relative amplitudes and interactions between convection organized into Rossby waves, Kelvin waves, MJO [62, 95], or TCs [39, 40॰]. Across these phenomena (convection to TCs to MJO), a common framework of analysis is to consider moist static energy variance budgets $[27,81,93,95$, 96]. Applying these diagnostics to aquaplanet simulations of TCs is an important avenue to understanding how the processes leading to organization in non-rotating or single-TC $f$-plane simulations are affected as more Earth-like geometry and thermal forcing are successively introduced.

Acknowledgements T. M. acknowledges the support of Natural Science and Engineering Research Council of Canada grant RGPIN-2014-05416 and a Canada Research Chair. We are grateful for thoughtful reviews by Dan Chavas and an anonymous review, comments from Nadir Jeevanjee, and editorial help from Alex Phucas.

\section{Compliance with Ethical Standards}

Conflict of Interest On behalf of all authors, the corresponding author states that there is no conflict of interest.

Open Access This article is distributed under the terms of the Creative Commons Attribution 4.0 International License (http:// creativecommons.org/licenses/by/4.0/), which permits unrestricted use, distribution, and reproduction in any medium, provided you give appropriate credit to the original author(s) and the source, provide a link to the Creative Commons license, and indicate if changes were made.

\section{References}

Papers of particular interest, published recently, have been highlighted as:

- Of importance

1. Emanuel K. 100 years of progress in tropical cyclone research. Meteorol Monogr 2019;59:15.1-15.68. This monograph covers a wide range of $\mathrm{TC}$ research from a historical perspective. 
2. Rotunno R, Emanuel KA. An air-sea interaction theory for tropical cyclones. Part II: Evolutionary study using a nonhydrostatic axisymmetric numerical model. J Atmos Sci 1987;44:542-561.

3. Vecchi GA, Swanson KL, Soden BJ. Whither hurricane activity? Science 2008;322:687-689.

4. Emanuel KA, Nolan DS. Tropical cyclone activity and the global climate system. Preprints, 26th Conf. on Hurricanes and Tropical Meteorology, Miami, FL, Amer. Meteor. Soc. A, vol 10; 2004.

5. Tippett MK, Camargo SJ, Sobel A. A Poisson regression index for tropical cyclone genesis and the role of large-scale vorticity in genesis. J Climate 2011;24:2335-2357.

6. Tang B, Camargo SJ. Environmental control of tropical cyclones in CMIP5: A ventilation perspective. J Adv Model Earth Syst 2014;6: $115-128$.

7. Sugi M, Noda A, Sato N. Influence of the global warming on tropical cyclone climatology: An experiment with the JMA global model. J Meteorol Soc Japan 2002;80:249-272.

8. Bengtsson L, Hodges KI, Esch M, Keenlyside N, Kornblueh L, Lou JJ, Yamagata T. How may tropical cyclones change in a warmer climate? Tellus 2007;59A:539-561.

9. Zhao M, Held IM, Lin SJ, Vecchi GA. Simulations of global hurricane climatology, interannual variability, and response to global warming using a 50-km resolution GCM. J Climate 2009;22:66536678 .

10. Zhao M, et al. Robust direct effect of increasing atmospheric $\mathrm{CO}_{2}$ concentration on global tropical cyclone frequency: A multimodel inter-comparison. US CLIVAR Variations 2013;11:17-24.

11. Wehner M, Reed KA, Stone D, Collins WD, Bacmeister J. Resolution dependence of future tropical cyclone projections of CAM5. 1 in the US CLIVAR Hurricane Working Group idealized configurations. J Climate 2015;28:3905-3925.

12. Camargo SJ, Wing AA. Tropical cyclones in climate models. Wiley Interdiscip Rev Clim Chang 2016;7:211-237. This review article describes GCM simulations of TCs, as well as other techniques that have been used to assess changes in TC activity.

13. Schenkel BA, Lin N, Chavas D, Vecchi GA, Oppenheimer M, Brammer A. Lifetime evolution of outer tropical cyclone size and structure as diagnosed from reanalysis and climate model data. $\mathrm{J}$ Climate 2018;31: 7985-8004

14. Zhao M, Held IM, Lin SJ. Some counterintuitive dependencies of tropical cyclone frequency on parameters in a GCM. J Atmos Sci 2012;69:2272-2283

15. Shaevitz DA. Coauthors: Characteristics of tropical cyclones in high-resolution models in the present climate. J Adv Model Earth Syst 2014;6:1154-1172.

16. Murakami H. Coauthors: Simulation and prediction of category 4 and 5 hurricanes in the high-resolution GFDL HiFLOR coupled climate model. J Climate 2015;28:9058-9079.

17. Knutson TR, McBride JL, Chan J, Emanuel K, Holland G, Landsea C, Held I, Kossin J, Srivastava AK, Sugi M. Tropical cyclones and climate change. Nat Geosci 2010;3:157-163.

18. Knutson TR, Tuleya RE. Impact of $\mathrm{CO}_{2}$-induced warming on simulated hurricane intensity and precipitation: Sensitivity to the choice of climate model and convective parameterization. J Climate 2004;17:3477-3495.

19. Nolan DS, Rappin ED, Emanuel KA. Tropical cyclogenesis sensitivity to environmental parameters in radiative-convective equilibrium. Quart J Roy Meteor Soc 2007;133:2085-2107.

20. Nolan DS, Rappin ED. Increased sensitivity of tropical cyclogenesis to wind shear in higher SST environments. Geophys Res Lett 2008;35(14):L14805.

21. Schneider T, O'Gorman PA, Levine XJ. Water vapor and the dynamics of climate changes. Rev Geophys 2010;48:RG3001. https:// doi.org/10.1029/2009RG000302.
22. Voigt A, Shaw TA. Circulation response to warming shaped by radiative changes of clouds and water vapour. Nat Geosci 2015;8: 102-106.

23. Kang SM, Frierson DMW, Held IM. The tropical response to extratropical thermal forcing in an idealized GCM: the importance of radiative feedbacks and convective parameterization. J Atmos Sci 2009;66:2812-2827.

24. Henry M, Merlis TM. The role of the nonlinearity of the StefanBoltzmann law on the structure of radiatively forced temperature change. J Climate 2019;20:335-348.

25. Emanuel K. Tropical cyclones. Annu Rev Earth Planet Sci 2003;31: 75-104.

26. Davis CA. The formation of moist vortices and tropical cyclones in idealized simulations. J Atmos Sci 2015; 72:3499-3516.

27. Wing AA, Camargo SJ, Sobel A. Role of radiative-convective feedbacks in spontaneous tropical cyclogenesis in idealized numerical simulations. J Atmos Sci 2016;73:2633-2642.

28. Murthy VS, Boos WR. Role of surface enthalpy fluxes in idealized simulations of tropical depression spinup. J Atmos Sci 2018;75: $1811-1831$

29. Montgomery MT, Smith RK. Recent developments in the fluid dynamics of tropical cyclones. Ann Rev Fluid Mech 2017;49: 541-574.

30. Hakim GJ. The mean state of axisymmetric hurricanes in statistical equilibrium. J Atmos Sci 2011;68:1364-1376.

31. Chavas DR, Emanuel K. Equilibrium tropical cyclone size in an idealized state of axisymmetric radiative-convective equilibrium. J Atmos Sci 2014;71:1663-1680.

32. Persing J, Montgomery MT, Smith RK, McWilliam JC. Quasi steady-state hurricanes revisited. Trop Cyclone Res Rev 2019;8: $1-17$.

33. Neale RB, Hoskins BJ. A standard test for AGCMs including their physical parametrizations: I: The proposal. Atmos Sci Lett 2000;1: 101-107.

34. Ballinger AP, Merlis TM, Zhao M, Held IM. The sensitivity of tropical cyclone activity to off-equatorial thermal forcing. J Atmos Sci 2015;72:2286-2302.

35. Gray WM. Hurricanes: Their formation, structure and likely role in the tropical circulation. Meteorology over the tropical oceans, pp. 155-218. Royal Meteorological Society. In: Shaw DB, editors; 1979.

36. Jeevanjee N, Hassanzadeh P, Hill S, Sheshadri A. 2017. A perspective on climate model hierarchies. J. Adv. Model. Earth Syst. pp. 1760-1771. This article describes novel categorizations of climate model hierarchies, which include broader range of model configurations than those discussed here.

37. Maher P, Gerber EP, Medeiros B, Merlis TM, Sherwood S, Sheshadri A, Sobel A, Vallis GK, Voigt A, Zurita-Gotor P. 2019. Model hierarchies for understanding atmospheric circulation. Rev. Geophys. p. in press.

38. Held IM. The gap between simulation and understanding in climate modeling. Bull Amer Meteor Soc 2005;86: 1609-1614.

39. Shi X, Bretherton CS. Large-scale character of an atmosphere in rotating radiative-convective equilibrium. J Adv Earth Model Syst 2014;6:616-629.

40. Merlis TM, Zhou W, Held IM, Zhao M. Surface temperature dependence of tropical cyclone-permitting simulations in a spherical model with uniform thermal forcing. Geophys Res Lett 2016;43: 2859-2865. This article compares simulations of spherical geometry with uniform thermal forcing to large-domain rotating RCE.

41. Viale F, Merlis TM. Variations in tropical cyclone frequency response to solar and $\mathrm{CO}_{2}$ forcing in aquaplanet simulations. $\mathrm{J}$ Adv Model Earth Syst 2017;9:4-18. 
42. Merlis TM, Zhao M, Held IM. The sensitivity of hurricane frequency to ITCZ changes and radiatively forced warming in aquaplanet simulations. Geophys Res Lett 2013;40:4109-4114.

43. Frierson DMW, Held IM, Zurita-Gotor P. A gray-radiation aquaplanet moist GCM. Part I: static stability and eddy scale. J Atmos Sci 2006;63:2548-2566.

44. Kang SM, Held IM, Frierson DMW, Zhao M. The response of the ITCZ to extratropical thermal forcing: Idealized slab-ocean experiments with a GCM. J Climate 2008;21:3521-3532.

45. Taylor KE, Stouffer RJ, Meehl GA. An overview of CMIP5 and the experiment design. Bull Amer Meteor Soc 2012;93(4):485-498.

46. Blackburn M, Williamson DL, Nakajima K, Ohfuchi W, Takahashi YO, Hayashi YY, Nakamura H, Ishiwatari M, McGregor JL, Borth $\mathrm{H}$, et al. The aqua-planet experiment (APE): control SST simulation. J Meteorol Soc Japan 2013;91:17-56.

47. Walsh KJE, Camargo SJ, Vecchi GA, Daloz AS, Elsner J, Emanuel K, Horn M, Lim YK, Roberts M, Patricola C, et al. Hurricanes and climate: the US CLIVAR working group on hurricanes. Bull Amer Meteor Soc 2015;96:997-1017.

48. Li F, Collins WD, Wehner MF, Leung LR. Hurricanes in an aquaplanet world: implications of the impacts of external forcing and model horizontal resolution. J Adv Model Earth Syst 2013;5(2):134-145.

49. Zhou W, Held IM, Garner ST. Tropical cyclones in rotating radiative-convective equilibrium with coupled SST. J Atmos Sci 2017;74:879-892.

50. Bell MM, Montgomery MT, Emanuel KA. Air-sea enthalpy and momentum exchange at major hurricane wind speeds observed during CBLAST. J Atmos Sci 2012;69:3197-3222.

51. Emanuel K, DesAutels C, Holloway C, Korty R. Environmental control of tropical cyclone intensity. J Atmos Sci 2004;61:843-858.

52. Mei W, Xie S-P, Primeau F, McWilliams JC, Pasquero C. Northwestern pacific typhoon intensity controlled by changes in ocean temperatures. Sci Adv 2015;1:e1500014.

53. Held IM, Zhao M. Horizontally homogeneous rotating radiativeconvective equilibria at GCM resolution. J Atmos Sci 2008;65: 2003-2013.

54. Zhou W, Held IM, Garner ST. Parameter study of tropical cyclones in rotating radiative-convective equilibrium with column physics and resolution of a 25-km GCM. J Atmos Sci 2014;71:1058-1069.

55. Khairoutdinov M, Emanuel K. Rotating radiative-convective equilibrium simulated by a cloud-resolving model. J Adv Model Earth Syst 2013;5:816-825.

56. Reed KA, Chavas DR. Uniformly rotating global radiativeconvective equilibrium in the Community Atmosphere Model, version 5. J Adv Model Earth Syst 2015;7:1938-1955.

57. Chan JCL. The physics of tropical cyclone motion. Annu Rev Fluid Mech 2005;37:99-128.

58. Held IM, Hou AY. Nonlinear axially symmetric circulations in a nearly inviscid atmosphere. J Atmos Sci 1980;37:515-533.

59. Kirtman BP, Schneider EK. A spontaneously generated tropical atmospheric general circulation. J Atmos Sci 2000;57:2080-2093.

60. Barsugli J, Shin SI, Sardeshmukh PD. Tropical climate regimes and global climate sensitivity in a simple setting. J Atmos Sci 2005;62: 1226-1240.

61. Horinouchi T. Moist Hadley circulation: Possible role of waveconvection coupling in aquaplanet experiments. J Atmos Sci 2012;69:891-907.

62. Pritchard MS, Yang D. Response of the superparameterized Madden-Julian oscillation to extreme climate and basic-state variation challenges a moisture mode view. J Climate 2016;29:49955008.

63. Walsh K. Climate theory and tropical cyclone risk assessment; 2019.

64. Chavas DR, Reed KA. 2019. Dynamical aquaplanet experiments with uniform thermal forcing: implications for tropical cyclone genesis and size. J. Atmos. Sci. https://doi.org/10.1175/JAS-D-190001.1. This article presents and compares theories for TC genesis and size in spherical geometry, uniform thermal forcing simulations.

65. Chavas DR, Reed KA, Knaff JA. Physical understanding of the tropical cyclone wind-pressure relationship. Nat Commun 2017;8: 1360. This article presents a theory for the wind-pressure relationship and assesses it in observations, comprehensive GCM simulations, and uniform thermal forcing aquaplanet simulations.

66. Corsaro CM. 2017. The $\beta$-effect in tropical cyclones: impact on intensity and sensitivity to temperature. Ph.D. thesis, Imperial College London, London UK.

67. Kossin JP. A global slowdown of tropical-cyclone translation speed. Nature 2018;558:104-107.

68. Korty RL, Emanuel KA, Huber M, Zamora RA. Tropical cyclones downscaled from simulations with very high carbon dioxide levels. J Climate 2017;30:649-667.

69. Kossin JP, Emanuel KA, Vecchi GA. The poleward migration of the location of tropical cyclone maximum intensity. Nature 2014;509: 349-352.

70. Fedorov AV, Muir L, Boos WR, Studholme J. 2018. Tropical cyclogenesis in warm climates simulated by a cloud-system resolving model. Clim. Dyn. pp. 1-21. This article investigates the effects of meridional temperature gradients, approaching the weak temperature gradient limit, on TC genesis in CRM simulations.

71. Bordoni S, Schneider T. Monsoons as eddy-mediated regime transitions of the tropical overturning circulation. Nat Geosci 2008;1: 515-519.

72. Donohoe A, Frierson DMW, Battisti DS. The effect of ocean mixed layer depth on climate in slab ocean aquaplanet experiments. Clim Dyn 2014;43:1041-1055.

73. Merlis TM. Does humidity's seasonal cycle affect the annual-mean tropical precipitation response to extratropical forcing. J Climate 2016;29:1451-1460.

74. Byrne MP, Pendergrass AG, Rapp AD, Wodzicki KR. Response of the intertropical convergence zone to climate change: location, width, and strength. Current Climate Change Reports 2018;4: 355-370.

75. Seo J, Kang S, Merlis TM. A model intercomparison of the tropical precipitation response to a $\mathrm{CO}_{2}$ doubling in aquaplanet simulations. Geophys Res Lett 2017; 44: 993-1000. This article has an intercomparison of ITCZ shifts in response to increased $\mathrm{CO}_{2}$ and shows that GCMs robustly simulate poleward shifts, with the magnitude sensitive to model parameterizations.

76. Bischoff T, Schneider T. Energetic constraints on the position of the intertropical convergence zone. J Climate 2014;27:4937-4951.

77. Emanuel K, Sobel A. Response of tropical sea surface temperature, precipitation, and tropical cyclone-related variables to changes in global and local forcing. J Adv Model Earth Syst 2013;5:447-458.

78. Sobel A, Camargo SJ, Hall TM, Lee CY, Tippett MK, Wing AA. Human influence on tropical cyclone intensity. Science 2016;353: 242-246.

79. O'Gorman PA, Allan RP, Byrne MP, Previdi M. Energetic constraints on precipitation under climate change. Surv Geophys 2012;33:1-24

80. Sobel A, Camargo SJ, Previdi M. 2019. Aerosol vs. greenhouse gas effects on tropical cyclone potential intensity and the hydrologic cycle. J Climate p. in press.

81. Kim D, Moon Y, Camargo SJ, Wing AA, Sobel A, Murakami H, Vecchi GA, Zhao M, Page E. Process-oriented diagnosis of tropical cyclones in high-resolution GCMs. J Climate 2018;31:1685-1702.

82. Camargo SJ, Emanuel KA, Sobel A. Use of a genesis potential index to diagnose ENSO effects on tropical cyclone genesis. J Climate 2007;20:4819-4834. 
83. Vimont DJ, Kossin JP. The Atlantic meridional mode and hurricane activity. Geophys Res Lett 2007;34: L07709.

84. Frisius T, Abdullah SMA. Nonlocality of tropical cyclone activity in idealized climate simulations. J Adv Model Earth Syst 2017;9: 3099-3115. This article is the first TC-permitting GCM study with idealized zonal asymmetries published.

85. Ballinger AP. 2015. Tropical cyclone activity in an aquaplanet general circulation model. Ph.D. thesis, Princeton University, Princeton NJ.

86. Defforge C. 2016. Evaluating the influence of sea surface temperature on tropical cyclone genesis: observations and simulations. Master's thesis, McGill University, Montreal, Canada.

87. Zarzycki CM, Levy MN, Jablonowski C, Overfelt JR, Taylor MA, Ullrich PA. Aquaplanet experiments using CAM's variableresolution dynamical core. J Climate 2014;27(14):5481-5503.

88. Harris LM, Lin SJ, Tu C. High-resolution climate simulations using GFDL HiRAM with a stretched global grid. J Climate 2016;29: 4293-4314.

89. Boos WR, Fedorov A, Muir L. Convective self-aggregation and tropical cyclogenesis under the hypohydrostatic rescaling. J Atmos Sci 2016;73:525-544.

90. Wing AA, Reed KA, Satoh M, Stevens B, Bony S, Ohno T. Radiative-convective equilibrium model intercomparison project. Geosci Model Dev 2018;11:793-813. This article describes a protocol for a non-rotating RCE intercomparison, including GCMs and CRMs. Extending the protocol to rotating model configurations is a promising approach for $\mathrm{TC}$ research.
91. Bretherton CS, Blossey PN, Khairoutdinov M. An energy-balance analysis of deep convective self-aggregation above uniform SST. J Atmos Sci 2005;62:4273-4292.

92. Muller CJ, Held IM. Detailed investigation of the self-aggregation of convection in cloud-resolving simulations. J Atmos Sci 2012;69: 2551-2565.

93. Wing AA, Emanuel KA. Physical mechanisms controlling selfaggregation of convection in idealized numerical modeling simulations. J Adv Model Earth Syst 2014;6:59-74.

94. Bony S, Stevens B, Coppin D, Becker T, Reed KA, Voigt A, Medeiros B. Thermodynamic control of anvil cloud amount. Proc Nat Acad Sci 2016;113:8927-8932.

95. Arnold NP, Randall DA. Global-scale convective aggregation: implications for the Madden-Julian Oscillation. J Adv Model Earth Syst 2015;7:1499-1518.

96. Muller CJ, Romps DM. Acceleration of tropical cyclogenesis by self-aggregation feedbacks. Proc Nat Acad Sci 2018;115:2930 2935.

Publisher's Note Springer Nature remains neutral with regard to jurisdictional claims in published maps and institutional affiliations. 